\title{
Atmospheric Brown Clouds- from science towards policy
}

\author{
S. Sherestha and M. Iyngararasan \\ United Nations Environment Programme
}

\begin{abstract}
Atmospheric Brown Clouds (ABCs) and its interaction with climate change is an emerging environmental issue. Studies demonstrate that $\mathrm{ABCs}$ and its interaction with build-up of greenhouse gases significantly affect the regional climate, glacial melting, hydrological cycle, agriculture and public health. For the next decades, the regional aerosol effects will continue to play a major role in environmental management as long as current strong sources of air pollution remain. An integrated multi-pollutant multi-sectoral approach for addressing atmospheric issues will result in optimum environmental and socioeconomic benefits. Regional intergovernmental networks have been established to address air pollution issues in different parts of the globe. These intergovernmental networks could be empowered to promote integrated approach for addressing the atmospheric environmental issues.
\end{abstract}

\section{Introduction}

This decade is witnessing profound human induced changes on Planet Earth. We have a population of over six billion, whose primary source of energy is fossil fuels and biomass burning. The per capita demand for energy is increasing. This demand has a direct impact on the total emissions of many air pollutants and greenhouse gases (GHGs), and on atmospheric environmental issues. This decade is also witnessing a major increase in both intensity and frequency of natural disasters.

After more than a century of scientific studies on GHGs today we have a fair understanding of the "global warming" problem. Scientific studies have revealed a new atmospheric issue: Atmospheric Brown Clouds (ABCs).

$\mathrm{ABCs}$ are the same as the aerosols that are mentioned in reports by the Intergovernmental Panel on Climate Change (IPCC). In principle, the tropospheric ozone is part of ABCs. Soot results from the incomplete combustion of fuels and consists of nano- to a few micro-metre (millionth of a metre) size particles. Black carbon (that is, light absorbing elemental and organic carbon particles) and many organic acids are the main constituents of soot. The brownish colour of ABCs is due to the absorption and scattering of solar radiation by anthropogenic black carbon, fly ash, soil dust particles, and nitrogen dioxide gas. Typical background concentrations of aerosols are in the range $100-300 \mathrm{~cm}^{-3}$, whereas in polluted continental regions the concentrations are in the range $1000-10000 \mathrm{~cm}^{-3}$. [1]

The ABCs are significantly affecting the earth's energy budget by intercepting solar radiation. United Nations Environment Programme (UNEP) commissioned Project ABC in collaboration with a team of distinguished scientists (ABC Science Team), based on a regional paradigm, with the science secretariat at the Center for Clouds, Chemistry and Climate $\left(\mathrm{C}^{4}\right)$, Scripps Institution of Oceanography (SIO) of the University of California at San Diego; and the secretariat for impacts and policy components at UNEP. Studies of Project ABC demonstrate that ABCs and its interaction with build-up of GHGs significantly affect the regional climate, glacial melt, water budget, agriculture and human

This is an Open Access article distributed under the terms of the Creative Commons Attribution-Noncommercial License 3.0, which permits unrestricted use, distribution, and reproduction in any noncommercial medium, provided the original work is properly cited. 
health. The studies also show that $\mathrm{ABCs}$ are frequently occurring phenomenon in and downwind of all heavily inhabited regions.

The widespread nature of $\mathrm{ABCs}$ and findings related to their adverse effects on climate, water budget, agriculture, human health and ecosystems have increased the need for development of science, capacity, and emission reduction measures in an integrated framework. Progress of Project ABC in development of science and capacity in addressing the ABCs issue are summarised in section 2 of this paper. Section 3 provides a summary of existing intergovernmental networks on air pollution and identifies the elements of integrated response to atmospheric environmental issues.

\section{Science}

Project ABC was established recognizing the need for additional science to deepen the under-standing of the source and role of aerosols in the interaction between air pollution and climate change. The main aim of the project is to develop sound science (based on reliable monitoring data over a long period) for integrated impact assessment such that it can be accompanied by appropriate capacity building measures and by development of appropriate mitigation steps, thus contributing to sustainable development. The project has made significant progress in the advancement of science and enhancement of capacity to study the combined impacts of GHGs and air pollution.

\subsection{Observatories}

The establishment of an integrated network of strategically located state-of-the-art ABC surface climate observatories throughout the Asia-Pacific region is a major achievement in this relatively poorly monitored part of the world. The observatories are now operated by local scientists, with regular training provided through the project and support extended by the Science Team. Many observatories are enhancements of existing observatories and a few are new. The objective of the observatories is to acquire continuous chemical and microphysical aerosol observations at key locations, with particular emphasis on black carbon and organics, as well as radiation, precipitation chemistry and meteorological measurements.

Currently, over a dozen ABC observatories are operational in Asia and the Pacific. These include the Maldives Climate Observatory $(\mathrm{MCOH})$ which is the first aerosol observatory in the Indian Ocean with a five-year time series data on the seasonal cycle and inter-annual variability in transport, aerosol chemistry and radiative forcing, and the Nepal Climate Observatory-Pyramid (NCO-P), the highest $\mathrm{ABC}$ observatory in the Himalayas documenting high soot levels at elevations as high as $5 \mathrm{~km}$.

In addition to regular monitoring at surface observatories, intensive field campaigns are conducted using unmanned aerial vehicles (UAVs) at given locations/regions. For example, Maldives Autonomous Unmanned Aerial Vehicles Campaign (MAC) during March-April 2004 based out of $\mathrm{MCOH}$, first of its kind in atmospheric measurements, the Cheju ABC Plume - Asian Monsoon Experiment (CAPMEX)-2008 was conducted in the spring of 2008 from a base on Cheju (Jeju) Island that deployed UAVs for the first time in East Asia. The measurements carried out during the campaign, when three UAVs are deployed in stacked formation with one flying above the cloud, one through the cloud and one below the cloud, helped to understand the interaction of dust and anthropogenic aerosols (for example, black carbon, sulphates) and atmospheric solar heating due to light-absorbing aerosols, among other effects.

Data collected at the observatories are being archived at the central data archival at the ABC-Data and Information Service Center (ABC-DISC). The data is also disseminated through the internet: http: //www .rrcap. unep.org/abc/data/index.cfm.

\subsection{Impact assessment}

The first assessment report on the impacts of ABCs was completed based on the observatory results, several international field campaigns and coordinated modeling studies. The assessment 
provide compelling evidences that due to higher concentrations of its constituents and extent of geographical coverage, ABCs can adversely alter directly and indirectly the regional and global climate change, the hydrological cycle such as pattern and intensity of monsoon precipitation, glacial melting, rainwater quality, and affect agriculture productivity, and human health.

Radiative Forcing: The absorption of solar radiation by the surface and the atmosphere is the fundamental driver for the physical climate system, the biogeochemical cycles, and for all life on the planet. $\mathrm{ABCs}$ have significantly altered this radiative forcing over polluted regions. It is certain that $\mathrm{ABC}$ s have caused dimming at the surface and soot in $\mathrm{ABC}$ s has increased solar heating of the atmosphere [2].

Glacial Melting: Scientific studies suggest that black carbon in ABCs is one of the major contributing factors in glacier and sea-ice melting. Simulation studies suggest that black carbon contributes to a warming of about $0.6^{\circ} \mathrm{C}$ in the lower and mid troposphere of the Himalayan region [3]. In addition, deposition of black carbon on snow or ice can reduce the surface albedo and accelerate melting.

Global Water budget: Digressing to all particles in ABCs, ABCs enhance scattering and absorption of solar radiation and also produce brighter clouds that are less efficient at releasing precipitation. These in turn lead to large reductions in the amount of solar radiation reaching Earth's surface (also known as dimming) and a corresponding increase in atmospheric solar heating. Together the ABCs dimming and microphysical effects can lead to a weaker hydrological cycle and drying of the planet which connects $\mathrm{ABCs}$ directly to availability of fresh water, a major environmental issue of the 21st century [4].

Crop Production: Aerosols and gaseous species in ABCs can impact crop production in a variety of ways (Fig. 1) by interfering in the basic needs of plants and by changing climatic conditions. They include: reduction of solar radiation, settling on plants, acidification of water and soil, reduction of photosynthesis capacity by ozone, effects on climatic conditions, and effects on hydrological cycle [1].

Health Impacts: The most serious health impacts of particles associated with the ABCs include cardiovascular and pulmonary effects leading to chronic respiratory problems, hospital admissions and deaths. Review of the available evidence indicates that there are likely to be very significant public health impacts from the ABCs [2].

\subsection{Regional Hotspots}

Spatial distribution of $\mathrm{ABCs}$ and regional hotspots around the world have been identified. The aerosol regional radiative forcing to climate system and associated impacts are intense and significant due to heterogeneous spatial and temporal distributions of aerosol loading. The particularly affected regions with high values of aerosol burden caused by human activities are Asia (e.g., South Asia, East Asia, Indonesian region), Africa (Southern and Central Africa), and South America (Amazon basin) and the oceanic region downwind (see Fig. 2). These are the regional hotspots, and the ABCs problem is not restricted to these regions only. For the next decades, the regional aerosol effects will continue to play a major role as long as strong sources of air pollution remain.

\subsection{Policy relevant messages}

Following policy relevant messages can be derived from the scientific studies:

- Traditional air pollutants in ABCs, such as black carbon and tropospheric ozone, play a significant role in global warming. The build-up of GHGs and ABCs poses major environmental threats to human health, water and food security. 


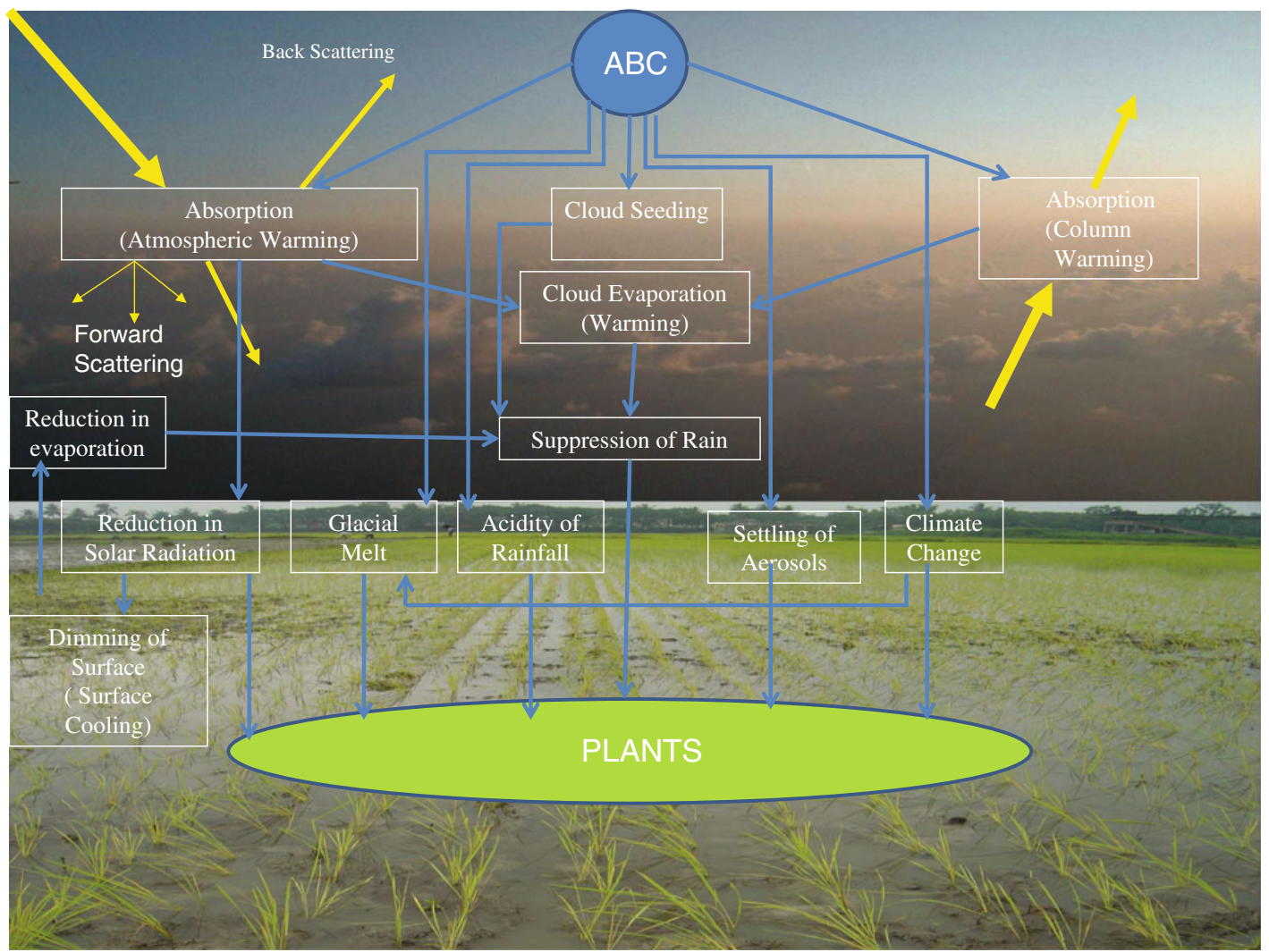

Fig. 1. Human activities are releasing large quantities of tiny particles (aerosols) into the atmosphere. Aerosols produce brighter clouds that are less efficient at releasing precipitation. The brighter clouds, scattering and absorption by aerosols in turn lead to large reductions in the amount of solar radiation reaching the earth's surface, a corresponding increase in atmospheric solar heating, changes in atmospheric thermal structure, surface cooling, disruption of regional circulation systems, such as monsoons, suppression of rainfall and less efficient removal of pollutants. Black carbon plays a major role in atmospheric solar heating and dimming of the surface. Manmade aerosols have dimmed the surface of the planet, while making it brighter at the top-of-the-atmosphere. Source: [1].

- Some aerosols in ABCs, like sulfates and nitrates reflect solar radiation and have a negative forcing (surface cooling effect) while black carbon absorbs solar radiation and has a net positive forcing (surface warming).

- Globally, black carbon has a net warming effect on the climatic system. Although the magnitude of its warming effect require more precise estimate, black carbon forcing has been estimated to be 20 to $50 \%$ of $\mathrm{CO}_{2}$ forcing, making it the second or third largest contributor to global warming [6].

- ABCs are short-lived. For example, the atmospheric life time of black carbon is on the order of a few weeks or less. Black carbon concentrations and their impacts on heating and human health will thus decrease almost immediately after emissions are reduced.

- Reduction in ABCs can be accomplished with already available, cost-effective technologies. For example, implementation of mitigation measures for black carbon emissions from diesel can be expanded as proven mitigation measures are already available. Available mitigation measures for black carbon emissions from the use of biomass for cooking are also available and are particularly important where such emissions may reach areas of snow and ice. 


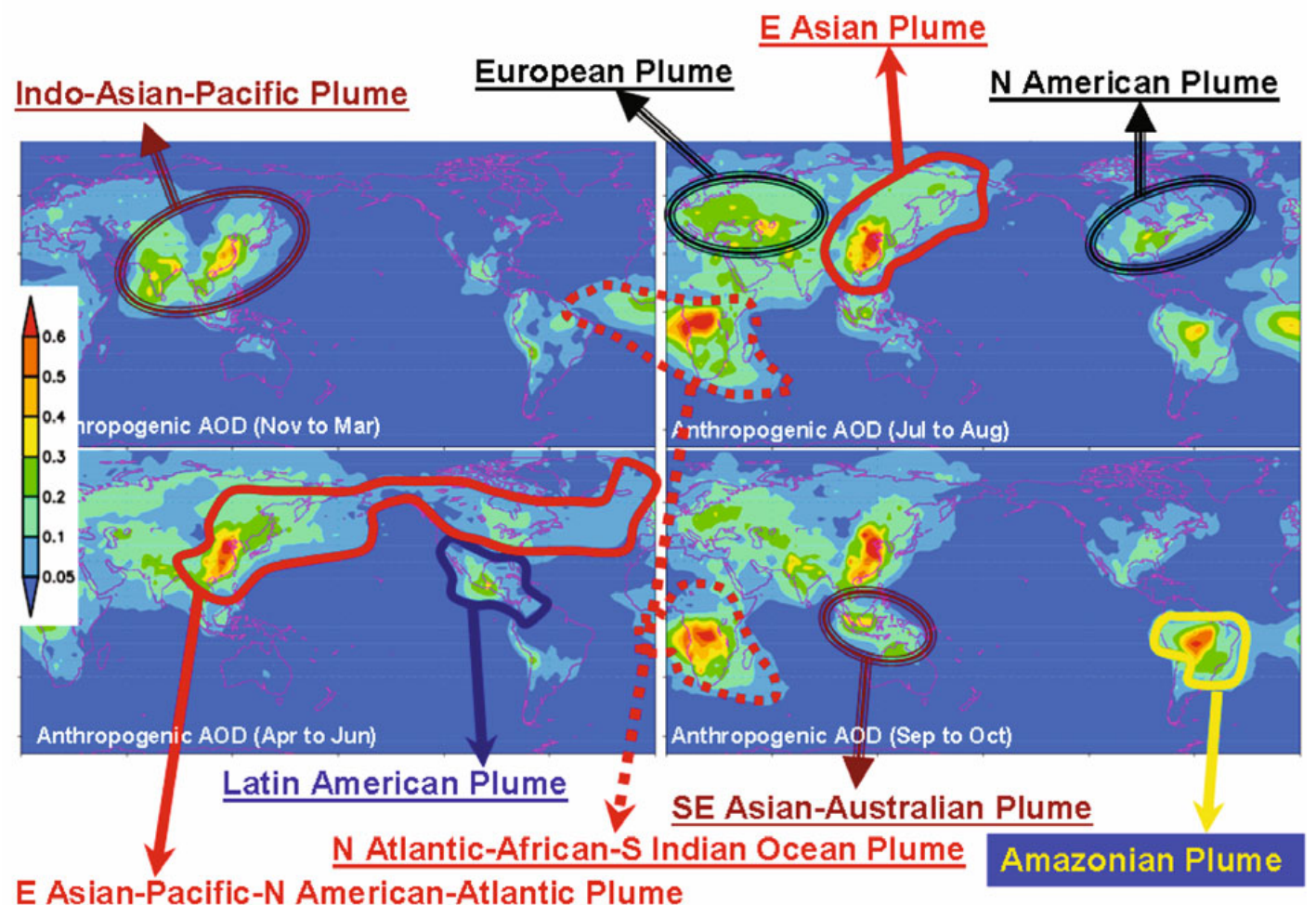

Fig. 2. The integrated satellite data shows anthropogenic aerosol optical depth (AOD) in the period 2001-2003 for four seasons. AOD is an index for the fraction of sunlight intercepted by particles and total aerosol concentration in the vertical column. The ABCs over South Asia peaked during the months of November-March. For July-August ABCs and dust reached peak values over Africa and Middle East. During the boreal spring, the $\mathrm{ABCs}$ and dust extended from East Asia across the North Pacific and further into Atlantic. The Amazonian Plume peaked during September to October. Source: [5].

\section{Policy response}

\subsection{Existing response}

Recognising the transboundary nature of atmospheric issues, a significant number of regional intergovernmental networks have emerged to tackle the problems in different parts of the globe.

In Europe and North America, the Convention on Long-range Transboundary Air Pollution (CLRTAP) provides the framework for regional cooperation on air pollution issues. CLRTAP was agreed in 1979 followed by eight specific legally-binding Protocols between 1984 and 1999.

In Asia, intergovernmental networks have been established at the sub-regional level. Countries in East and Southeast Asia have initiated scientific cooperation under the Acid Deposition Monitoring Network in East Asia (EANET). In South Asia, eight countries have formally agreed to cooperate under the framework of the Male Declaration on Control and Prevention of Air Pollution and its Likely Transboundary Effects for South Asia (Malé Declaration). Countries of Southeast Asia have agreed on a formal treaty on the control of haze pollution from forest fires/ clearance; and the Central Asian Republics have adopted an environmental treaty considering air pollution as a major issue. Sub-regional level networks are collaborating at the regional level through the Joint Forum on Atmospheric Environment in Asia and the Pacific since 2009.

Intergovernmental air pollution networks are also emerging in Africa. Southern African countries are collaborating under the Lusaka Agreement on Air Pollution. Countries in Eastern Africa have 
established the Eastern African Regional Framework Agreement on Air pollution. Countries in West and Central Africa adopted the West and Central Africa Regional Framework Agreement on Air Pollution (Abidjan Agreement). Countries in North Africa are in advanced stage of reaching an agreement for regional cooperation on air pollution.

Countries in Latin America and the Caribbean have initiated discussions on a framework agreement on air pollution in Latin America and the Caribbean and in advanced stage of adoption of the framework.

While the existing and emerging intergovernmental networks largely focusing on air pollution related issues, they provide the framework for implementation of integrated response to atmospheric environmental issues.

\subsection{Integrated response}

Atmospheric environmental issues such as indoor air pollution, urban air pollution, regional air pollution, and climate change are interrelated. Thus disconnected and isolated policy responses to atmospheric issues will have unintended consequences for the climate and possibly trigger non-linear changes. An example of an isolated policy response is the reduction of sulphur emissions (to mitigate health impacts of air pollution) without a comparable reduction in carbon dioxide and black carbon emissions, which can lead to a large increase in the warming during the coming decades. An integrated approach will result in optimum environmental and socioeconomic benefits. Such integrated response could include monitoring, impact assessment, adaptation, and mitigation measures under a multi-pollutant multi-sectoral framework.

Developing countries severely lack the required capacity to address the atmospheric issues under integrated framework. There is a need to develop the science and build the capacity of developing countries for monitoring and assessment of air pollution/atmospheric changes, their impacts and development of preventive, adaptation and mitigation measures. Regional co-operation has proved to be an effective instrument for addressing these issues and existing intergovernmental networks could provide the platform for promoting the integrated approach. The existing regional and sub regional initiatives need to be strengthened and widened in mandate to incorporate the integrated approach.

\section{References}

1. V. Ramanathan, M. Agrawal, H. Akimoto, M. Auffhammer, H. Autrup, L. Barregard, P. Bonasoni, M. Brauer, B. Brunekreef, G. Carmichael, W.-C. Chang, U. K. Chopra, C.E. Chung, S. Devotta, J. Duffus, L. Emberson, Y. Feng, S. Fuzzi, T. Gordon, A.K. Gosain, S.I. Hasnain, N. Htun, M. Iyngararasan, A. Jayaraman, D. Jiang, Y. Jin, N. Kalra, J. Kim, M. G. Lawrence, S. Mourato, L. Naeher, T. Nakajima, P. Navasumrit, T. Oki, B. Ostro, Trilok S. Panwar, M.R. Rahman, M.V. Ramana, H. Rodhe, M. Ruchirawat, M. Rupakheti, D. Settachan, A. K. Singh, G. St. Helen, P. V. Tan, S.K. Tan, P.H. Viet, J. Vincent, J.Y. Wang, X. Wang, S. Weidemann, D. Yang, S.C. Yoon, J. Zelikoff, Y.H. Zhang and A. Zhu, Atmospheric Brown Clouds: Regional Assessment Report with Focus on Asia. (United Nations Environment Programme, 2008)

2. V. Ramanathan, M. Agrawal, H. Akimoto, M. Aufhammer, S. Devotta, L. Emberson, S.I. Hasnain, M. Iyngararasan, A. Jayaraman, M. Lawrance, T. Nakajima, T. Oki, H. Rodhe, M. Ruchirawat, S.K. Tan, J. Vincent, J.Y. Wang, D. Yang, Y.H. Zhang, H. Autrup, L. Barregard, P. Bonasoni, M. Brauer, B. Brunekreef, G. Carmichael, C.E. Chung, J. Dahe, Y. Feng, S. Fuzzi, T. Gordon, A.K. Gosain, N. Htun, J. Kim, S. Mourato, L. Naeher, P. Navasumrit, B. Ostro, T. Panwar, M.R. Rahman, M.V. Ramana, M. Rupakheti, D. Settachan, A. K. Singh, G. St. Helen, P. V. Tan, P.H. Viet, J. Yinlong, S.C. Yoon, W.-C. Chang, X. Wang, J. Zelikoff and A. Zhu (2008), Atmospheric Brown Clouds: Regional Assessment Report with Focus on Asia- Summary for Policy Makers, (United Nations Environment Programme, 2008)

3. V. Ramanathan and G. Cermichael, Global and Regional Climate Changes Due to Black Carbon (2008) 
4. V. Ramanathan, Science of Black Carbon and Climate Change, Black Carbon e-Bulletin (United Nations Environment Programme, July 2009)

5. V. Ramanathan, F. Li, M.V. Ramana, P.S. Praveen, D. Kim, C.E. Corrigan, H. Nguyen, E.A. Stone, J.J. Schauer, G.R. Carmichael, B. Adhikary, S.C. Yoon, Atmospheric brown clouds: Hemispherical and regional variations in long-range transport, absorption, and radiative forcing, J. Geophys. Res. 112:D22S21, doi:10.1029/2006JD008124 (2007)

6. F. S. Wallack and V. Ramanathan, The Other Climate Changers: Why Black Carbon and Ozone Also Matter (2009) 